to de Dejours ${ }^{1}$ sobre "Desejo ou motivação: uma interrogação psicanalítica sobre o trabalho" poderia ter enriquecido a discussăo. Ainda assim, faltaria uma discussão que relacionasse a sublimaçăo no trabalho e o próprio exercício da sexualidade.

Parece inevitável que as fantasias, mesmo que não se concretizem, rondem a mente de colegas e que uma atraçăo mais ou menos erotizada esteja presente nas relaçôes de trabalho. Como lidar com elas? Por ser um livro dinigido às empresas, poderia conter algumas sugestōes sobre esse assunto. Também duvidosa é a posição do autor de que, com a entrada das mulheres no mercado de trabalho, a organizaçẩo desse setor tenha se aproximado do modo feminino de se comportar. Apesar disso, ainda que com algumas lacunas, o livro pode auxiliar as pessoas que trabalham a compreender o tena, já que o relacionamento amoroso no trabalho tem sido mais vivido do que estudado.

1. DEJOURS, C. Desejo ou motivação: uma interrogação psicanalím tica sobre o trabalho. In: DEJOUFS, C ABDOUCHELI, E. J. C. Psicodinanica do trabalho: uma contribulcado da escola dejouriana à analise da relaçầo sofrimento-prazer no trabalho. Sâo Paulo: Atlas, 1994.

\section{THE JAPANESE ENTERPRISE SYSTEM: COMPETITIVE STRATEGIES AND COOPERATIVE STRUCTURES}

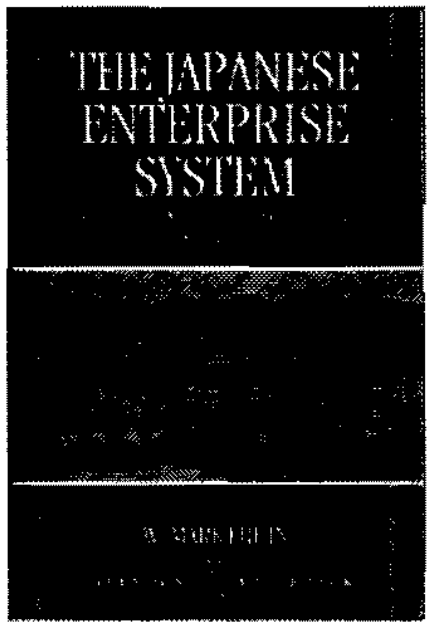

de W. MARK FRUIN

Oxford: Clarendon Press, 1992, 397p.

por Gilmar Masiero, Pesquisador e Professor da Universidade Estadual de Maringá, PR.
M ark Fruin é professor e díretor do Banco do Canadá, pesquisador do Instituto de Pesquisa e Política da Ásia-Pacifico e também professor e pesquisador da Universidade da Colümbia Britânica, no Canadá. No início da década de 80 trabalhou dois anos na Harvard Business School com o professor Alfred D. Chandler. Nesses dois anos, Fruin escreveu e publicou pela Harvard University Press, em 1993, Kikkoman: company, clan and community.

O professor Chandler diz que o atual livro de Fruin "mi estabelecer o estágio para a discussĩo do sistema de negócios japonés e das estruturas e estratégins de suas empre. sas por mutos anos". Chalmers Johnson, outro importante acadêmico americano que estuda o Japäo, diz que "este é o melhor livo sobre a estrutura industrial japonesa em qualquer lingua*.

A observação do professor Johnson certamente estä associada ao fato de Fruin ter domínio dos idiomas inglêse japonês. Baseado na produção acadêmica escrita nesses dois idiomas e em muitas entrevistas e documentos das próprias empresas, Mark Fruin escreve oito capítulos sobre a ongem e o desenvolvimento das estruturas cooperativas e estratégias competitivas que caracterizam a sociedade industrial japonesa.

Acompanhando o desenvolvimento das duzentas maiores empresas industriais do Japäo nos anos focais de 1918, 1930, 1954, 1973 e 1987, o autor escreve: 1. A história e a lógica da interdependência; 2 . 0 ambiente institucional; 3. A invençẫo do sistema empresarial; 4. A definiçâo do sistema empresarial; 5. O aprimoramento do sistema empresarial; 6. Fábricas focais; 7. Redes entre empresas; 8. Dinâmica e interdependência estruturada. Cada um desses capitulos, elaborados na tradiçāo dos trabalhos sobre a business history america. na, contêm mais de 50 notas que servem para esclarecer determinados pontos e indicar o vasto domínio bibliográfico e jornalistico do autor.

Na apresentaçäo do livro, lê-se que ele foi elaborado fundindo quatro correntes de interpretação da evoluçâo e emergência da liderança de empresas industriais japonesas durante o século $X X$. Primeiro, fornece um estudo histórico das instituições industriais do Japão moderno. Segundo, identifica as formas básicas de interaçāo econômico-sociais no Japăo. Terceiro, estuda o desenvolvimento do sistema de negócios japonês em circunstâncias de rápidas mudanças técnicas a econômicas. Finalmente, mostra a estratégia utilizada pela gerência japonesa para responder e moldaruse a essas mesmas circunstâncias.

Essa quádrupla síntese, continua a apresentação, oferece um modelo de desenvolvimento institucional sob condiçōes de desenvolvimento económico tardio e iniciativa privada que se situam em algum lugar entre o desenvolvimento capitalista de Estado e a economia de 
livre mercado. As políticas de negócios săo mais enfatizadas que as politicas industriais, revelando um conjunto de robustas instituiçôes e uma dinâmica para ativá-las e inter-relacioná-las.

As robustas instituiçôes sâo resultado do processo de desenvolvimento econômico japonês sintetizado no capítulo 2. Aí o autor apresenta os principais eventos da história da industrialização japonesa, procurando caracterizar os três tipos de empresa discutidos no restante do livro. Enterprise type interfirm type e factory type săo analisados no transcorrer dos períodos de 1890-1920; $1920-55$ e $1955-2000$.

Este livro de Fruin "é motivado pela busca do que é diferente nas empresas japonesas, no contexto da industrializaçāo mundial. A mais óbvia e impressionante diferença é encontrada na estrutura". Buscando descrever as estruturas industriais japonesas, $o$ autor enfatiza interaçōes entre os indivíduos, entre estes e as instituiçốes e entre as próprias instituiçốes. O resultado săo 397 páginas de excelente argumentaçäo teórica com exemplificaçôes da realidade cotidiana. Os capítulos 6 e 7 abordam as experiências da Toshiba e da Toyota, respectivamente.

Fruin estuda o sistema empresarial japonês como sendo resultado da importação e adaptação de modelos e tecnologias ocidentais à realidade oriental, ou, mais precisamente, japonesa. No Japāo, o processo de adaptação empresarial, a cada vez mais rápidas e imprevisíveis mudanças sociais, criou segundo o autor as três formas de organização industrial acima mencionadas e que, juntas, formam o Japanese Enterprise System. Enfatizando os processos de acting interdependently e learning to leam continuosly de maneira mais acentuada que aspectos economico-financeiros, o autor caracteriza o dinamismo industrial japonês.

Os motivos pelos quais os japoneses - e não os coreanos ou chineses - desenvolveram a estrutura industrial descrita por Fruin nâo são considerados de maneira convincente. Aspectos relacionados ao comércio internacional de mercadorias ou de patentes industriais também não foram explorados pelo autor. Empolgado por alguns indicadores de crescimento econômico, ele năo vê outros aspectos, como as longas jornadas de trabalho, as elevadas poupanças pủblica e privada, muitas vezes em detrimento do próprio bem-estar, e o relativamente baixo poder de compra dos trabalhadores japoneses. Não yê também setores econômicos como o da construçâo civil, aeroespacial ou qualquer outro de produção näo-seriada, onde o desempenho japonês estâ longe da excelência.

Independentemente do que o autor viu ou deixou de ver, as economias de escala, os tipos de aprendizagem $e$ de transação, săo extensivamente estudados em The Japanese enterprise system para caracterizar suas estrutu- ras cooperativas e suas estratégias competitivas. Dessa maneira, o livro deve ser lido por economistas, industriais, estudiosos da história econômica e de negócios, administradores em geral, e por todos os estudiosos do Japão.

\section{O BRASIL QUE DÁ CERTO: O NOVO CICLO DE CRESCIMENTO 1994-2005}

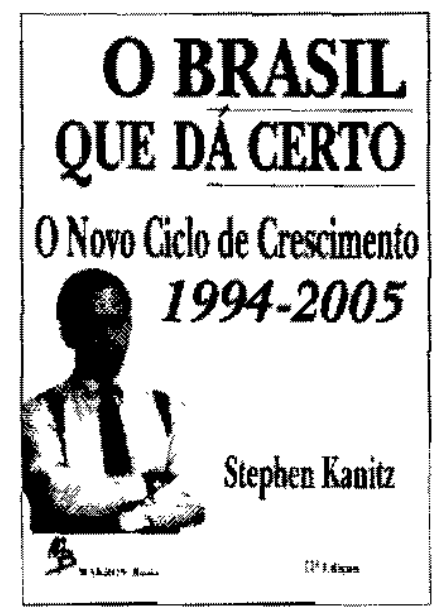

de STEPHEN CHARLES KANITZ

Säo Paulo: Makron Books, 1994, $100 \mathrm{p}$.

por Newton Hirata, Graduando em Administraçáo da Fundaçāo Universidade Estadual de Maringá.

U ma boa dose de otimismo, 30 gráficos, dez tabelas, muita informação, pequenos e grandes detalhes sobre a economia brasileira integram o cenário elaborado por Stephen Charles Kanitz, em seu livro O Brasil que dá certo: o nooo ciclo de crescimento. 1994-2005. Além disso, fatos a partir da década de 60 e projeçōes até 2005 săo analisados exaustivamente pelo autor, numa relação sempre dicotomica entre pontos positivos e negativos.

A obra se inicia com fatos da década de 60 , quando 0 pais começou a receber a poupança externa (empréstimos) e o capital externo (multinacionais) que promoveram o milagre econômico da década de 70 . Este milagre aconteceu, segundo o autor, em virtude do montante de recursos financeiros externos aplicados nos diversos setores da economia brasileira. Os investimentos geravam uma elevada taxa de retorno, entre $20 \%$ a $25 \%$ ao ano, com um custo muito baixo, de somente $3 \%$. 